\title{
O psicólogo e as demandas escolares - considerações sobre a formação continuada
}

\author{
Janaína Aparecida Silva Lopes', https://orcid.org/0000-0002-8148-286X \\ Silvia Maria Cintra da Silva ${ }^{1}$, https://orcid.org/0000-0003-0834-5671
}

\begin{abstract}
Resumo
A formação continuada do psicólogo que trabalha com demandas escolares ainda é um tema pouco explorado na literatura; contudo, de acentuada relevância. Este artigo relata uma pesquisa de cunho qualitativo que teve como objetivo compreender as concepções sobre formação continuada de psicólogos que trabalham com demandas escolares a partir de sua formação inicial, prática e experiências de formação continuada, na região do Triângulo Mineiro. Foram entrevistados quatro psicólogos que atuam em espaços educacionais diversos. Constatamos que existe certo distanciamento entre a concepção de formação continuada e os modos como desenvolvem essa formação. Três mencionaram um referencial teórico pouco consolidado ou inexistente, o que se reflete tanto nos desafios apontados quanto nos relatos em relação à própria formação continuada. As concepções sobre formação continuada distanciam-se do compromisso social, mas também destacamos as condições desfavoráveis para a busca desta formação, como a falta de oferta de cursos e condições precárias de trabalho.
\end{abstract}

Palavras-chave: Psicologia escolar; formação profissional; atuação do psicólogo.

\section{Psychologist and school demands - considerations about continuing education}

\begin{abstract}
The continuing formation of the psychologist who works with school demands is still an unexplored topic in the literature; however, of great relevance. This article reports a qualitative research whose objective was to understand the conceptions about the continuous formation of psychologists who work with school demands from their initial formation, practice, and experiences of continuous formation, in the Triângulo Mineiro region. Four psychologists were interviewed who work in diverse educational spaces. We find that there is a certain distance between the conception of continuing education and the ways in which it is developed. Three mentioned a theoretical framework that was not consolidated or nonexistent, which is reflected both in the challenges pointed out and in the reports regarding the continuous formation itself. Conceptions about continuing education are distanced from social commitment, but we also highlight the unfavorable conditions for the pursuit of this training, such as the lack of courses and precarious working conditions.
\end{abstract}

Keywords: School psychology; professional education; psychologist's performance.

\section{El psicólogo y las demandas escolares - consideraciones sobre la formación continuada}

\begin{abstract}
Resumen
La formación continuada del psicólogo que trabaja con demandas escolares aun ha sido un tema poco explorado en la literatura; sin embargo, de acentuada significación. En este artículo se relata una investigación de cuño cualitativo que tuvo como objetivo comprender las concepciones sobre formación continuada de psicólogos que trabajan con demandas escolares a partir de su formación inicial, práctica y experiencias de formación continuada, en la región del Triángulo Minero. Se entrevistaron a cuatro psicólogos que actúan en espacios educacionales diversos. Constatamos que existe cierto distanciamiento entre la concepción de formación continuada y los modos como desarrollan esa formación. Tres mencionaron un referencial teórico poco consolidado o inexistente, lo que se reflete tanto en los desafíos apuntados cuanto en los relatos en relación a la propia formación continuada. Las concepciones sobre formación continuada se distancian del compromiso social, pero también destacamos las condiciones desfavorables para la búsqueda de esta formación, como la falta de oferta de cursos y condiciones precarias de trabajo.
\end{abstract}

Palabras clave: Psicología escolar; formación profesional; actuación del psicólogo.

1 Universidade Federal de Uberlândia - Uberlândia - MG - Brasil; janaina.psicologia@yahoo.com.br; silvia@ufu.br 


\section{Introdução}

A formação continuada em Psicologia Escolar é considerada como parte de um compromisso social do psicólogo com as questões da escola, pois desde os primórdios do surgimento da Psicologia como ciência e profissão, a área vem mantendo uma relação complexa e contraditória com a Educação (Antunes, 2003; Barbosa, 2012; Pfromm Netto, 1996). Do surgimento das escolas normais até a instalação dos primeiros laboratórios experimentais, a Psicologia, segundo Antunes (2014, p.81) se servia de um "campo potencial de aplicação dos conhecimentos e técnicas derivadas da ciência psicológica". Contudo, à medida que vai se consolidando como ciência autônoma, torna-se clara sua postura política e ideológica que, conforme Bock (2000), foi isolando os sujeitos de seu mundo social e assumindo uma visão de homem a partir da noção de natureza humana, defendendo a ideia de que todas as condições de vida são dadas pela sociedade e que o sucesso ou fracasso é de responsabilidade de cada um.

Com o reconhecimento da profissão em 1962, pela Lei Federal $n^{\circ} 4.119$ (1962), o período que segue a profissionalização é de vertiginosa expansão na oferta de cursos de Psicologia pelo Brasil. Nesse momento, a Psicologia passa a se distanciar da área da Educação e um dos fatores, de acordo com Mello (1975) e Cruces (2010), pode ser explicado pelo currículo dos cursos de formação, que privilegiava o modelo clínico de atuação, pautado na psicometria e nos psicodiagnósticos, dificultando a formação de outros modos de atuação.

Desta maneira, as práticas tradicionais, com viés organicista e determinista, resultam no afastamento do psicólogo das práticas pedagógicas, voltando sua atenção para o indivíduo que não aprende. Antunes (2003) indica o início da década de 70 como o período em que a Psicologia passa a ser duramente criticada pelo uso indiscriminado de testes psicológicos e pelos impactos que esses causavam nos educandos. No final da referida década, um grupo de psicólogos ${ }^{2}$, ainda sob o regime ditatorial, começa a se articular politicamente com o objetivo de propor um projeto de Psicologia mais engajado com as causas populares (Prates, 2015).

Na década de 80 , as produções de Maria Helena Souza Patto contribuem de forma significativa para fortalecimento da crítica e da denúncia de práticas hegemônicas incompatíveis com as necessidades educacionais. Segundo Barbosa (2012), até esse momento a Psicologia se servia de teorizações estrangeiras e o rompimento com essa visão tradicional permitiu uma compreensão dos processos educativos de forma ampla, crítica e em consonância com a realidade educacional do país.

Para Guzzo, Mezzalira, Moreira, Tizzei e Silva Neto (2010), o modelo de atuação pautado na predição e no controle é o responsável pela "raiz política de exclusão da escola" (p.133) ao contribuir para a classificação dos alunos

2 Sérgio Antonio da Silva Leite, Yvonne Alvarenga Gonçalves Khouri, Wanda Maria Junqueira de Aguiar, Ana Mercês Bahia Bock, Abelardo de Almeida e Maria Aparecida C. Cunha (Prates, 2015). segundo suas aptidões (ou não) para a aprendizagem e permanência na escola. Conforme Tanamachi e Meira (2003), a Educação deve permitir aos homens se apropriarem dos bens produzidos pela humanidade por meio da socialização do conhecimento historicamente acumulado e, assim, nesse processo, possibilitar-Ihes a humanização. À Psicologia caberia, portanto, garantir a apropriação desse conhecimento promovendo práticas emancipatórias e humanizadoras, sendo ela agente potencialmente transformador.

Apesar de não caber apenas à Psicologia a tarefa de transformação das práticas educacionais, consideramos, conforme Martínez (2009), que precisamos assumir um compromisso social com a transformação dessas práticas ao tomarmos o compromisso social como um elemento constitutivo da formação do psicólogo.

Diante do exposto, o objetivo principal do presente trabalho é conhecer e analisar as necessidades de formação continuada de psicólogos que trabalham com demandas escolares $^{3}$ a partir de sua formação inicial, prática e experiências de formação continuada, na região do Triângulo Mineiro. Para tanto, seguiremos com algumas considerações importantes acerca da formação inicial e continuadae, ainda, com apontamentos sobre os desafios da prática.

\section{Formação continuada: da formação inicial passando pelas experiências profissionais}

A formação inicial tem respondido a muitas críticas feitas em relação às práticas tradicionais (Mello, 1975; Patto, 1984; Cruces, 2006; M. Souza, 2009) de tal modo que se torna inviável tratar da importância da formação continuada do psicólogo escolar, sem levar em conta tais aspectos. Mello (1975) destaca que o currículo dos primeiros cursos de Psicologia apresentava uma ênfase na formação voltada para a área clínica, prejudicando a formação de outros modelos de atuação, que direta ou indiretamente, poderiam influenciar a opção dos egressos pela área, conforme a autora.

Para Cruces (2009), essa marca foi constatada em estudos que mostraram que o psicólogo ingressava no mercado de trabalho despreparado para o manejo de situações postas por uma demanda real de problemas da população brasileira. No que tange à atuação na área escolar, evidenciava-se a distância entre a formação do profissional e seus modos de compreender e intervir nas questões educativas. Outros estudos subsequentes (Patto, 1984; Antunes, 2003; Cruces, 2010) foram confirmando essa condição dada na formação inicial e, ao mesmo tempo, denunciando as práticas tradicionais, adaptacionistas.

$\mathrm{Na}$ tentativa de sanar problemas decorrentes da formação inicial, em 2004 foram implementadas as Diretrizes

3 Consideramos nesta pesquisa o psicólogo escolar como aquele que trabalha com demandas escolares, independente do seu local de trabalho, baseadas na definição de psicólogo escolar apontada por Tanamachi e Meira (2003); segundo as autoras, não é local que define o psicólogo escolar, mas sim seu comprometimento com as questões escolares. 
Curriculares Nacionais para os cursos de Graduação em Psicologia (DCNs) ${ }^{4}$ (Parecer 0062/2004, 2004), para que houvesse uma melhor articulação entre teoria e prática, privilegiando-se uma formação básica e geral, atenta às necessidades locais e ao compromisso social da profissão, por meio das ênfases constantes no projeto pedagógico dos diversos cursos.

Contudo, apesar da implementação das DCNs, algumas pesquisas demonstram que a formação inicial ainda não conseguiu suplantar modelos tradicionais de intervenção, necessária ao entendimento das demandas educacionais (Souza, Silva, \& Yamamoto, 2014; Silva, Silva, Peretta, Nasciutti, \& Naves, 2014; Seixas, 2014; Cruces, 2009). Conforme Seixas (2014), ainda existem impasses entre as diretrizes e os Projetos Pedagógicos de cada curso, sendo que muitos não conseguiram contemplar os diferentes modos de atuação do psicólogo, mantendo ainda uma formação conteudista e a clínica como campo hegemônico. Como resultado, a prática do psicólogo tem refletido as contradições de sua formação, que oscila entre "práticas extremamente críticas e inovadoras e atuações permeadas pela visão curativa e individualizada, que é denunciada por ser estigmatizadora e por fazer recair sobre o próprio indivíduo a culpa pelo problema." (Cruces, 2010, p. 27).

Para diversas autoras (Tanamachi \& Meira, 2003; Maluf, 2007; M. Souza, 2009), o psicólogo escolar tem sido tratado como aquele que "resolve problemas" da escola, mais especificamente com foco nos alunos que "não aprendem". Neste sentido, a superação das práticas descontextualizadas necessita de profissionais que tenham clareza quanto às bases teóricas e práticas capazes de compreender os problemas educacionais, de forma concreta e comprometida.

Conhecer os limites e possibilidades de sua atuação é apontado por Meira (2000) como necessário, visto que não cabe somente ao psicólogo a responsabilidade pelos processos de mudança educacional. Ademais, ao considerarmos a insuficiência da formação inicial e as dificuldades dos psicólogos em compreenderem a complexidade e as especificidades do contexto educacional, entendemos a formação continuada como uma condição importante para a superação das práticas tradicionais. Mas que tipo de formação continuada poderá contribuir de fato com a prática do psicólogo escolar?

Para Fagan (1996, citado por Guzzo, 2011, p. 89) "tornar-se Psicólogo Escolar é nunca chegar a ser um Psicólogo Escolar, pois para responder às mudanças sociais no contexto educacional, nunca se está pronto... é preciso que se construa a cada dia." Nesse sentido, a formação do psicólogo escolar precisa ser compreendida não como uma mera especialização ou uma aprendizagem superficial de técnicas, como menciona Novaes (2011), mas uma formação humana, promotora de humanização, de transformação de práticas e posturas.

Acreditamos que a maneira como os psicólogos escolares têm se apropriado dos processos de formação,

4 CNE/CES, Parecer 0062/2004. seja inicial ou continuada, influencia diretamente no compromisso social que a Psicologia busca assumir. Entendemos, conforme Duarte (2001), que a formação pode promover tanto os processos de humanização quanto os processos de alienação, cabendo aos sujeitos a finalidade que dedicam à sua ação.

Segundo Guzzo e cols. (2010), a compreensão da realidade em que se atua é essencial quando se busca um corpo de conhecimento que forneça uma produção capaz responder às demandas dessa realidade; neste caso, uma Psicologia crítica.

Assim, dada a devida importância aos fatores que contribuem para uma prática comprometida socialmente com as transformações educacionais, e considerando a relevância de uma formação continuada pautada pelo viés da Psicologia Escolar crítica, seguiremos com o percurso metodológico.

\section{Percurso Metodológico}

A pesquisa foi realizada levando em consideração os pressupostos qualitativos, por nos permitir uma leitura crítica capaz de instigar reflexões que nos levem à compreensão do fenômeno e não a sua quantificação (Gonzaléz-Rey, 2002). Para tal, utilizamos a entrevista semiestruturada e o diário de bordo (Bogdan \& Biklen, 1994) como recursos metodológicos, mais condizentes com o objetivo da pesquisa.

Os participantes do estudo foram quatro psicólogos que trabalham com demandas escolares na região do Triângulo Mineiro, sendo uma psicóloga da rede pública de educação, uma que atua no espaço da clínica, um psicólogo que trabalha com demandas do ensino médio em uma escola da rede privada, e outra psicóloga, também de escola privada, que atende ao ensino infantil e fundamental. Para encontrá-los, fizemos uma busca na rede social Facebook e na lista telefônica online, usando a terminologia "psicólogo escolar". A princípio não foi delimitado o número de participantes, mas estipulamos um número mínimo de três psicólogos, sendo que a cada entrevista transcrita e analisada, verificávamos a possibilidade ou não de acrescentar novos participantes ao estudo, guiando-nos pelo critério de saturação de dados, descrito por Bogdan e Biklen (1994).

A partir da identificação dos primeiros psicólogos, entramos em contato pela citada rede social e via e-mail, esclarecendo o objetivo da pesquisa e solicitando um agendamento para a realização das entrevistas. O roteiro de entrevista abarcou os seguintes aspectos: tempo de formação; considerações sobre a formação inicial (considerando disciplinas e estágios); tempo de atuação na área; desafios da prática; referencial teórico-metodológico utilizado; considerações sobre formação continuada (concepção de formação continuada e experiências de formação continuada). Após a realização das entrevistas, estas foram transcritas e posteriormente transcriadas, permitindo que na transformação da linguagem oral para a escrita, o texto se tornasse mais claro, facilitando a compreensão do leitor (Meihy, 1998). 
A seguir, realizamos uma leitura atenta e exaustiva das transcriações com o auxílio do método de análise de conteúdo de Bardin (2004) para: identificação dos conteúdos recorrentes na entrevista; apreensão dos temas subjacentes aos conteúdos identificados e nomeação e definição das categorias que agrupavam os conteúdos referentes aos temas identificados. Deste modo, definimos as categorias ou eixos de análises que correspondem, segundo a autora, à transformação por meio dos recortes de modo a agregar, permitindo a preparação para a análise de conteúdo.

Nas análises, elencamos três eixos: 1. formação inicial; 2. atuação na área/prática; e 3. formação continuada, considerando os elementos que mais se ressaltaram na leitura das transcrições a partir do objetivo deste estudo e considerando também o referencial teórico da Psicologia Escolar Crítica que nos embasa.

\section{Resultados e Discussão}

\section{Formação inicial}

Julgamos a formação inicial como um dos importantes eixos de investigação para o alcance de nosso objetivo. Embora esta pesquisa trate de formação continuada, entendemos que só é possível abordá-la considerando primeiramente a formação no Ensino Superior que dá suporte ao futuro profissional. A formação acadêmica, aqui chamada de formação inicial, diz respeito à graduação em Psicologia. $\mathrm{Na}$ formação inicial, os conteúdos teóricos e práticos constituem relevante arcabouço instrumental para a prática do psicólogo.

Neste eixo, foi possível constatarmos que todos os psicólogos participantes tiveram acesso às disciplinas de Psicologia Escolar e aos referenciais críticos, bem como às práticas disciplinares e estágios na área. Outro dado importante é que todos se formaram com base no currículo mínimo, anterior ao estabelecimento das DCNs.

Dos quatro participantes, destacamos que apenas um não vislumbrava a possibilidade de atuar na área escolar. Três tiveram interesse pela área e buscaram maior aproximação. O psicólogo que não tinha interesse pela área justificou que a ênfase nas disciplinas da área escolar era pouca, quando comparada à área clínica, por exemplo.

Dois psicólogos fizeram referência ao caráter generalista do curso como sendo um fator que limitaria o entendimento do aluno quanto às especificidades exigidas pela área escolar. Para um deles, sua formação generalista não foi capaz de dar a devida ênfase à área escolar, contribuindo para seu desinteresse inicial pela área: "a escolar... educacional, acho que ela não é nem $2 \%$ do curso, isso não dá pra cativar ninguém, na minha opinião." Já outro participante fala sobre os riscos de se atuar a partir de uma formação generalista, sem uma formação continuada: "A gente leva salada de fruta sem ter muito discernimento. Não é intencional. Mas eu acho complicado, assim, eu não conheço uma pessoa que tem tanto discernimento já saindo direto da graduação."

Entendemos que a generalidade do curso é necessária, e as próprias diretrizes curriculares sustentam esse caráter, destacando a relevância das ênfases, dentro do compromisso social do psicólogo com a profissão. Quando o profissional tem clareza acerca da insuficiência em sua formação devido a esse caráter generalista, acreditamos que são maiores as possibilidades de investir em sua formação continuada do que quando ele sente-se pronto para trabaIhar em qualquer área assim que recebe o diploma.

De modo geral, as disciplinas e os estágios deram aos psicólogos as primeiras impressões sobre a prática do psicólogo escolar. Para duas psicólogas, foram as disciplinas que proporcionaram o interesse pela área. Uma delas relata: "E aí foram as disciplinas que tinham conexão com a Psicologia Escolar que foram me despertando mais, assim interesse. Interesse, curiosidade, questionamento, vontade de estudar."

Para outra psicóloga, apesar de julgar a teoria importante, foi na vivência dos estágios que a teoria fez sentido: “... em termos de conhecimento só fui ter quando começou a parte dos estágios. A parte prática mesmo. Que aí eu considero que eu aprendi muito, porque eu já estava mais madura e comecei a entender o que era, de fato".

Outro psicólogo não conseguiu se interessar pela Psicologia Escolar durante o curso, apesar de ter tido oportunidade de cursar disciplinas pelo viés da Psicologia Escolar crítica e estagiar na área: "...a Psicologia Escolar nunca foi minha favorita na época da graduação."

Dentre as três psicólogas que já manifestavam interesse pela Psicologia Escolar, os estágios colaboraram para efetivação desse interesse. No trecho a seguir é possível perceber a trajetória de uma delas pela Psicologia Escolar, na graduação.

Gostei demais de uma disciplina na Psicologia Escolar que eu fiz na área, Psicologia Escolar 2, com uma professora específica que eu fiz e depois fui monitora dessa mesma disciplina... Depois fui monitora com essa mesma professora de uma disciplina da licenciatura em psicologia, na minha época tinha licenciatura. E aí eu comecei estudar mais, a ficar mais próxima, depois com essa mesma professora e mais um outro grupo de professores, que estavam juntos num estágio em Psicologia Escolar, aí eu fiz esse outro estágio e fiquei lá, fiquei acho que dois anos nesse estágio. Só em Psicologia Escolar.

Os estágios, para Silva Neto (2014), Pires (2011) e Silva (2005) são espaços singulares de formação, por possibilitarem ao aluno conhecer a realidade prática do psicólogo escolar, além de promover o diálogo com a teoria, dando sentido e significado a esta.

O valor dado a cada situação é diverso de indivíduo para indivíduo, por serem seres históricos, com realidades diferentes e condições diferentes para apreensão crítica da realidade. Conforme Martínez (2007), cada pessoa tem 
seu próprio tempo, modos e condições de aprendizagem e desenvolvimento a partir das mediações que lhe são propiciadas durante a graduação. Assim, salienta os problemas que um currículo fragmentado, sem espaços de interdisciplinaridade, pode ocasionar.

É uma colcha de retalhos com que o profissional terá que lidar e encontrar a forma para elaborar coerentemente seu percurso profissional (Martínez, 2007). Sem consciência de tal processo, poderá comprometer a sua prática e até mesmo prejudicar os sujeitos com quem irá trabalhar.

\section{Atuação na área de Psicologia Escolar}

Neste eixo, considerando que o psicólogo escolar foi constituindo seu fazer a partir da sua atuação em vários espaços, e também assim delineado por Tanamachi e Meira (2003, p. 11) que "o que define um psicólogo escolar não é o seu local de trabalho, mas o seu compromisso teórico e prático com as questões da escola", buscamos compreender os desafios enfrentados pelos psicólogos que trabalham com demandas escolares desde sua inserção na área, as atividades que desenvolvem e o referencial teórico que sustenta suas práticas.

A inserção na área aconteceu de modo diverso para os quatro psicólogos deste estudo. A condição pós-formação nos proporciona a ideia da complexidade de fatores que constituem esse momento na vida dos sujeitos. Percebemos sentimentos como insegurança, angústia, frustração e desânimo. O psicólogo que trabalha com demandas escolares em uma escola privada de ensino médio, mesmo sem interesse pela área na sua formação inicial, decidiu aceitar a vaga de psicólogo escolar: "eu vim pra cá mais porque eu precisava de dinheiro do que gostar, de paixão, pela educacional. Essa paixão, esse gostar, veio depois". No seu percurso após a graduação, buscou inicialmente a área clínica - sua preferida - mas que não lhe propiciou o retorno financeiro esperado.

A psicóloga que trabalha no espaço da clínica relata que apesar de ter se identificado com a Psicologia Escolar na graduação, ao se formar, teve dúvidas quanto ao caminho a seguir, decidindo pelo mestrado. As outras duas psicólogas não tiveram dúvidas quanto ao interesse pela área escolar; no entanto, enfrentaram muitas dificuldades para conseguir espaço dentro das escolas. Uma delas, atuante na rede pública de educação, ciente das dificuldades de inserção na área, fez uma segunda formação em Pedagogia e por intermédio de concursos nesta área, foi conquistando seu espaço de psicóloga, ainda que no início contratada como pedagoga.

A psicóloga que trabalha em escola privada atendendo à demanda do ensino infantil e fundamental apresentou-se perante várias escolas, sem sucesso. Diante da frustração, iniciou um trabalho como psicóloga clínica e divulgando o trabalho da clínica, - depois de um bom tempo - conseguiu uma parceria com uma escola.
Cruces (2006, p.148) sugere algumas hipóteses sobre as dificuldades de inserção do psicólogo nas escolas, como
a própria falta de interesse dos formandos em psicologia em atuarem nessa área, abrindo espaços para os psicopedagogos; ao desconhecimento das possibilidades de atuação profissional neste campo, tanto por leigos quanto por profissionais da área; e ao fato de que há profissionais que não executam bem seu trabalho, não são capazes de atender a demanda de determinada instituição.

Para Carvalho (1982, citado por Cruces, 2006), na escolha da área de atuação, existe uma influencia mútua da formação inicial recebida, dos interesses pessoais e do mercado de trabalho, que também consideramos neste estudo. Em relação às atividades executadas, sabemos que são vastas as possibilidades de desenvolvimento pelos psicólogos escolares dentro do contexto de sua atuação. Contudo, percebemos que aqueles que trabalham na rede privada ainda mantêm o foco no aluno.

O psicólogo que trabalha com demandas do ensino médio desenvolve algumas atividades que poderiam ser consideradas inovadoras, como os projetos dentro e fora da escola relacionados às profissões e relacionamentos interpessoais. Todavia, as práticas tradicionais ainda são mantidas, como: aconselhamento, acolhimento e orientação ao aluno. Conforme Cruces (2010), na área escolar o modelo de atuação crítico e inovador convive junto com os modelos de visão curativa e individualizada, sendo estes fortemente denunciados por culpabilizarem os indivíduos pelos problemas de aprendizagem.

Na prática da psicóloga que trabalha com o ensino infantil e fundamental, o olhar também é voltado para o aluno, cabendo ao psicólogo o ajuste daqueles que não se adaptam: "O que eu mais faço é acompanhar as crianças em sala de aula."

Os dois psicólogos executam outras atividades como orientação a pais, orientação aos professores e encaminhamentos sem, contudo, superarem o isolamento profissional, vislumbrando um trabalho mais próximo junto às equipes escolares. Para Meira (2003), precisamos romper com a imagem do psicólogo escolar como um técnico "e pensá-lo com um elemento mediador que - junto com educadores, alunos, funcionários, direção, famílias e comunidade - poderá avaliar criticamente os conteúdos, métodos de ensino e as escolhas didáticas que a escola faz como um todo" ( $p$. 53, destaque da autora).

A psicóloga que trabalha no espaço da clínica e outra que trabalha no setor público dispõem de uma condição de trabalho um pouco mais favorável, do ponto de vista da autonomia. Além do mais, diante dessa condição de trabalho menos rígida, elas têm conseguindo avaliar melhor a complexidade das relações escolares, dialogando com outros atores envolvidos no processo.

Para os quatro psicólogos, lidar com professores e pais é o grande desafio da atuação, sendo que apenas uma 
entrevistada menciona seu esforço em aprender a dialogar com esses atores, assumindo para si tal responsabilidade. Refletindo sobre os desafios enfrentados, constatamos que grande parte deles surge da dificuldade dos psicólogos em fundamentarem sua prática a partir de um referencial teórico. De acordo com Guzzo (2007), mesmo que o psicólogo consiga perceber o problema em sua complexidade, ele não dispõe de fundamentos teóricos e práticos suficientes para romper com o modelo dominante devido a sua formação tradicional. No caso deste estudo, dentre os quatro psicólogos, duas assumiram um referencial crítico, sendo que uma demonstra inconstância entre o discurso e a prática crítica. Outros dois não explicitaram um referencial teórico. Abaixo, trecho da fala de um destes psicólogos.

$\mathrm{Na}$ clínica eu não sou psicanalista, eu não sou comportamental, eu uso de todos os recursos que eu acho necessário. Se eu acho que aquela criança vai se beneficiar fazendo uns relaxamentos eu uso desse recurso que é da terapia ericksoniana, mas aquela criança ali, aquela outra, precisa de um quadrinho, de um quadro de rotina e que se ela ganhar uma estrelinha vai funcionar bem pra ela, então eu utilizo. Já com essa outra eu acho que isso não funciona, entendeu? Então, eu não tenho muito um filósofo só. Por exemplo, eu não sigo só Piaget, eu não sigo só o Vigotski, eu leio muito, então, eu vou com o que eu aprendo assim, no meu dia-dia, eu não tenho um teórico só, não.

Tem sido comum o uso de referenciais teóricos incompatíveis com a complexidade do objeto estudado, ecletismos teóricos, ou mesmo uma suposta ausência de qualquer referencial teórico nas práticas cotidianas dos psicólogos escolares (Silva \& cols., 2012; Meira, 2000; C. Souza, 2010; Souza, Silva, \& Yamamoto, 2014). Consideramos de suma importância o uso de um referencial teórico condizente com a realidade educacional, proporcionando uma leitura crítica capaz de promover a transformação e a emancipação sociais. Além do mais, colabora para o enfrentamento dos desafios enfrentados por meio de uma visão ampliada dessa realidade, ao levar em conta a multiplicidade de aspectos inerentes à condição humana.

\section{Formação continuada}

A formação continuada do psicólogo nos remete ao compromisso social da Psicologia com a Educação. Para tanto, ao pensarmos a formação continuada do psicólogo escolar, levando em consideração as especificidades da área, o caráter complexo e contraditório presentes no espaço escolar e a importância do trabalho em equipe e do diálogo para a promoção dos processos de transformação e emancipação sociais, convém ponderarmos que não se trata de qualquer formação, mas de uma formação crítica, que situe o tempo histórico, as condições sociais, culturais e políticas acerca da complexidade que envolve as questões escolares.
Acreditamos que a maneira como os psicólogos escolares têm se apropriado dos processos de formação, seja inicial ou continuada, influencia diretamente no compromisso social que a Psicologia almeja atender. Neste sentido, buscamos junto aos psicólogos que trabalham com demandas escolares compreender suas concepções a respeito da formação continuada e como tem sido o desenvolvimento da própria formação.

Para os quatro participantes, a formação continuada está relacionada à ação de continuar estudando, independentemente da modalidade de formação (especialização, aperfeiçoamento, mestrado, doutorado, cursos, palestras, congressos, entre pares, supervisão, grupos de estudo, dentre outras). Contudo, percebemos que dois psicólogos esperam que a formação continuada seja capaz de fornecer técnicas e informações que atendam as suas necessidades imediatas. É importante salientar que eles não explicitam o uso de um referencial teórico para embasamento de suas práticas.

$\mathrm{Na}$ fala de um deles é possível percebermos que a formação continuada antes de ser compreendida como processo de transformação de práticas, é vista pelo olhar econômico, de mercado: "Eu não me formei em nenhuma da área escolar. Eu tenho um planejamento de fazer algum curso, alguma pós na área de gestão escolar, já pensando em progredir na carreira."

Outra psicóloga, que relata embasar sua prática a partir do materialismo histórico-dialético, buscou uma formação continuada em neuropsicologia, por acreditar que a sua teoria de base não fosse suficiente para responder as demandas que envolvem, segundo ela, os diagnósticos ${ }^{5}$ de TDAH.

\section{Existem crianças que podem ter sim, esse transtorno [TDAH]... a neuropsicologia me ajudou a compreender outras questões. Porque tem questões que somente a dialética ou essa perspectiva do materialismo histórico ela não explica, ela não explica. Precisa de outros conhecimentos.}

Deste modo, ao mesmo tempo em que busca respaldar sua formação continuada por meio de uma leitura crítica da realidade, entende as dificuldades de aprendizagem a partir da vertente tradicional, orgânica, individual, que tanto a Psicologia vem lutando para superar.

Segundo Meira (2003), ter acesso a referenciais teóricos críticos, incorporar o discurso crítico, não garante uma prática efetivamente crítica, apesar da importância da teoria. Ainda assim, concordamos com Novaes (2011, p. 122) que "é fundamental superar os desvios de uma simples especialização dos cursos de formação, um superficial aprendizado de técnicas e estratégias sem fundamentação e contextualização, o isolamento profissional e o modismo teórico."

Apesar de três dos quatro psicólogos não terem ainda consolidado sua prática por uma vertente crítica, de modo a

5 Para uma leitura mais concisa sobre a crítica aos supostos transtornos, indicamos a seguinte leitura: Conselho Regional de Psicologia de São Paulo (2010). Medicalização de crianças eadolescentes: conflitos silenciados pela redução de questões sociais a doenças de indivíduos. São Paulo: Casa do Psicólogo. 
colaborar mais efetivamente com os processos educativos na emancipação dos sujeitos, uma psicóloga destaca-se apresentando uma postura indagadora e problematizadora da realidade educacional, ao mesmo tempo em que busca, por meio de uma formação continuada, a própria transformação, pessoal e profissional. Contemplando a formação continuada pela sua dimensão ampla, essa psicóloga nos fala que a formação deve ser capaz de gerar transformação pessoal e profissional. "Porque o que é formação mesmo é o que te conecta mesmo com sua prática. Tem que ter uma práxis ali, uma dialética, tem que promover transformação em você e no que você está fazendo ao mesmo tempo, sabe."

Segundo Maluf (2007) o psicólogo precisa desenvolver conhecimentos sobre Educação, em seu sentido amplo, que considere os aspectos filosóficos, políticos e histórico-sociais. Infelizmente, um ponto importante considerado por todos os psicólogos é a quase ausência de cursos de formação continuada na área da Psicologia Escolar e até mesmo de cursos de áreas afins à Educação, confirmado por Cruces (2006).

Deste modo, precisamos ter o cuidado de não culpabilizarmos os psicólogos que, conforme Bock (2000), ainda têm pouca consciência de suas ações devido à formação com forte influência liberal e positivista, que enfatiza o olhar para o indivíduo. Entretanto, consideramos que a formação continuada é uma oportunidade de rompimento com ações cristalizadoras e engessadas que tanto têm promovido a exclusão e as desigualdades sociais.

\section{Considerações finais}

A formação inicial e a prática profissional do psicólogo escolar nos fornecem importantes elementos de análise, nos permitindo afirmar que a formação continuada é condição necessária para efetivação das práticas transformadoras e emancipatórias nos contextos educacionais. Apesar de pouco discutida pela área da Psicologia Escolar, desempenha um importante papel na reavaliação da prática, a partir dos desafios enfrentados pelos psicólogos que trabalham com a demanda escolar.

Diante de uma formação hegemônica, que ainda mantém seu caráter conteudista e predominantemente clínico, mesmo após a implementação das DCNs, assumir um compromisso com a transformação das práticas educacionais tem se tornado um desafio para a profissão. Ademais, convém enfatizarmos que o caráter generalista da formação inicial, apesar de bastante explorado na literatura quanto a sua influência nas práticas descontextualizadas, não é o real problema dessa formação, mas sim as dificuldades de se compreender as especificidades de cada área e buscar, por meio da formação continuada, o complemento necessário para se desenvolver um trabalho de qualidade.

Neste estudo foi possível percebemos que ela tem sido concebida tanto pelo caráter técnico, caracterizando uma busca por respostas pontuais para os desafios complexos - muitas vezes atendendo a questões mercadológicas quanto pelo caráter processual, que se caracteriza por uma busca pelo complemento da formação inicial, generalista - nem sempre consciente da importância dessa formação.

Além do mais, é possível compreendermos que a concepção de formação continuada tende a se distanciar daquela que os psicólogos participantes buscam conforme a maior ou menor apropriação que estes tenham tido do referencial teórico crítico. Ou seja, quanto maior a consistência teórico-metodológica, mais consciente pode ser a atuação e maior o comprometimento do profissional com as demandas escolares.

Os desafios apresentados pelos psicólogos que trabalham com demandas escolares nos chamam a atenção para a necessidade de um referencial teórico crítico que sustente e dê sentido as práticas e que está diretamente relacionado às dificuldades encontradas na prática. Constatamos que ainda são comuns as demandas para o atendimento às individualidades, sejam elas direcionadas aos alunos, pais ou professores, bem como o isolamento das práticas no interior das escolas, que ficou mais evidente em relação às práticas dos psicólogos que trabalham em instituições privadas. Apesar de relatarem certa autonomia em suas atividades, são tolhidos quanto a intervenções mais amplas, atendendo às expectativas mais imediatas da escola.

Apesar de vastas as modalidades de formação continuada, todos os psicólogos enfatizaram a carência de formação continuada, na região, voltada para a área educacional. Ressaltamos que além da quase ausência de oferta de cursos, ainda recaem sobre os profissionais as condições precárias de trabalho, com insuficientes ou excessivas jornadas de trabalho, salários baixos e falta de políticas públicas para assegurar sua participação junto às equipes escolares.

Assim, não pretendemos prescrever modos de formação continuada ou mesmo de esgotar as possibilidades de discussão; acreditamos que ainda são necessários mais estudos que contribuam para o fortalecimento das ações formativas em Psicologia Escolar, em destaque a formação continuada, inclusive levando em consideração as mudanças no currículo, a partir das DCNs. As universidades e entidades de representação como a ABRAPEE e sindicatos também devem se mobilizar para garantir a oferta e a qualidade da formação continuada aos profissionais que estão na linha de frente do trabalho.

Consideramos, portanto, que a formação continuada, longe de servir como mercadoria, moeda de troca por melhores salários, precisa ser percebida em sua essência, em sua condição (re)vitalizadora. Longe de trazer todas as respostas, esta deve ser capaz, numa vertente crítica, de auxiliar o profissional a lidar com as incertezas, com as constantes mudanças, de promover a reflexão pessoal e profissional, importante para os processos de formação continuada, e que atenda assim, ao compromisso social da profissão.

\section{Referências}

Antunes, M. A. (2003). Psicologia e Educação no Brasil: um olhar histórico-crítico. In: Meira, M. E.; Antunes, M. A. (Orgs.), Psicologia Escolar: teorias críticas (pp. 139-168). São Paulo: Casa do 
Psicólogo.

Antunes, M. A. (2014). A Psicologia no Brasil: leitura histórica sobre sua constituição (5a ed.). São Paulo: EDUC.

Barbosa, D. R. (2012). Contribuições para a construção da historiografia da psicologia educacional e escolar no Brasil. Psicologia Ciência e Profissão, 32(especial), 104-123.

Bardin, L. (2004). Análise de conteúdo. Lisboa: Edições 70.

Bock, A. M. (2000). As influências do Barão de Munchhausen na psicologia da educação. In: Tanamachi, E. R.; Proença, M.; Rocha, M. L. (Orgs.), Psicologia e educação: desafios teórico-práticos (pp. 11-34). São Paulo: Casa do Psicólogo.

Bogdan, R.; Biklen, S. (1994). Investigação qualitativa em educação: uma introdução à teoria e aos métodos. Portugal: Porto Editora.

Conselho Regional de Psicologia de São Paulo (2010). Medicalização de crianças e adolescentes: conflitos silenciados pela redução de questões sociais a doenças de indivíduos. São Paulo: Casa do Psicólogo.

Cruces, A. V. (2006). Egressos de cursos de psicologia: preferências, especializações, oportunidades de trabalho e atuação na área educacional.(Tese de doutorado). Universidade de São Paulo, Instituto de Psicologia, São Paulo.

Cruces, A. V. (2009). Desafios e perspectivas para a psicologia escolar com a implantação das diretrizes curriculares. In: MarinhoAraujo,C. M. (Org.), Psicologia escolar: novos cenários e contextos de pesquisa, formação e prática (pp. 15-34). Campinas: Alínea.

Cruces, A. V. (2010). Psicologia e educação: nossa história e nossa realidade. In: Almeida,S.F. (Org.), Psicologia escolar: ética e competências na formação e atuação profissional (3a ed., pp. 1736). Campinas: Alínea.

Duarte, N. (2001). Educação escolar, teoria do cotidiano e a escola de Vigotski (3a ed.). Campinas: Autores Associados.

González-Rey, L. F. (2002). Pesquisa qualitativa em psicologia: caminhos e desafios. São Paulo: Pioneira Thomson Learning.

Guzzo, R. S. (2007). Escola amordaçada: compromisso do psicólogo com esse contexto. In: Martínez, A. M. (Org.), Psicologia Escolar e compromisso social: novos discursos, novas práticas (2a ed., pp. 17-29). Campinas: Alínea.

Guzzo, R.S. (2011). Formando psicólogos escolares no Brasil: dificuldades e perspectivas. In: Wechsler, S.M. (Org.), Psicologia escolar: pesquisa, formação e prática (4 ed., pp. 63-79). Campinas, SP: Alínea.

Guzzo, R. S.; Mezzalira, A. S.; Moreira, A. P.; Tizzei, R. P.; Silva Neto, W. M. F. (2010). Psicologia e educação no Brasil: uma visão da história e possibilidades nessa relação. Psicologia: Teoria e Pesquisa, 26(número especial), 131-141.

Lei $n^{\circ}$. 4.119 de 27 de agosto de 1962 (1962, 27 de agosto). Dispõe sobre os cursos de formação em Psicologia e regulamenta a profissão de psicólogo. Brasília, DF: Presidência da República.

Maluf, M. R. (2007). O psicólogo escolar e a alfabetização. IN: Martínez.A.M. (Org.), Psicologia escolar e compromisso social: novos discursos, novas práticas (pp. 67-92). Campinas, SP: Alínea.

Martínez, A. M. (2007). O psicólogo escolar e os processos de implantação de políticas públicas: atuação e formação. In: Campos, H. R. (Org.), Formação em psicologia escolar: realidades e perspectivas (pp. 109-134). Campinas: Alínea.

Martínez, A. M. (2009). Psicologia escolar e educacional: compromissos com a educação brasileira. Psicologia Escolar e Educacional, 13(1), 169-177.

Meihy, J. C. (1998). Manual de História oral (2a ed.). São Paulo: Edições Loyola.

Meira, M. E. (2000). Psicologia escolar: pensamento crítico e práticas profissionais. In: Tanamachi, E. R.; Proença, M.; Rocha, M. L. (Orgs.), Psicologia e educação: desafios teórico-práticos (pp. 3572). São Paulo: Casa do Psicólogo.

Meira, M. E. (2003). Construindo uma concepção crítica de psicologia escolar: contribuições da pedagogia histórico-crítica e da psicologia sócio-histórica. In: Meira, M. E.; Antunes, M. A. (Orgs.), Psicologia escolar: teorias críticas (pp. 13-78). São Paulo: Casa do Psicólogo.

Mello, S. L. (1975). Psicologia e profissão em São Paulo. São Paulo: Ática.

Novaes, M. H. (2011). Visão Transdisciplinar na formação do psicólogo escolar. In: Wechsler, S. M. (Org.), Psicologia escolar: pesquisa, formação e prática (4a ed., pp. 115-124). Campinas, SP: Alínea.

Parecer 0062/2004. (2004, 19 de fevereiro). Fixa as Diretrizes Curriculares Nacionais para os cursos de graduação em Psicologia. Brasília: Ministério da Educação, Conselho Nacional de Educação/Câmara de Educação Superior.

Patto, M. H. (1984). Psicologia e ideologia: uma introdução crítica à psicologia escolar. São Paulo: T. A. Queiroz.

Pfromm Netto, S. (1996). As origens e o desenvolvimento da psicologia escolar. In: Wechsler, S. M. (Org.), Psicologia Escolar: pesquisa, formação e prática (1 ed., pp. 21-38). Campinas, SP: Alínea.

Pires, V. S. (2011). O processo de subjetivação profissional durante os estágios supervisionados em psicologia. (Dissertação de 
mestrado). Universidade Federal de Uberlândia, Programa de Pós-Graduação em Psicologia, Uberlândia.

Prates, E. F. (2015). Os encontros de psicólogos da área da educação (1980-1982): um projeto de psicologia escolar e educacional em São Paulo.(Dissertação de mestrado). Pontifícia Universidade Católica de São Paulo, Mestrado em Psicologia Social, São Paulo.

Seixas, P. D. (2014). A formação graduada em psicologia no Brasil: reflexão sobre os principais dilemas em um contexto pós-DCN. (Tese de doutorado). Programa de Pós-Graduação em Psicologia, Universidade Federal do Rio Grande do Norte, RN.

Silva Neto, W. M. F. (2014). Supervisão de estágio em psicologia escolar: contribuições de psicologia crítica à formação e à prática do supervisor. (Tese de doutorado). Pontifícia Universidade Católica de Campinas, Campinas.

Silva, S. M. C. (2005). Psicologia escolar e arte: uma proposta para a formação e atuação profissional. Campinas, SP: Alínea e EDUFU.

Silva, S. M. C.; Lima, C. P.; Silva, A. C. O.; Rezende, P. C. M.; Carrijo, R. S.; Ribeiro, M. J.; Mazzuchelli, D. S. R.; Barreto, V. S. (2012). O psicólogo diante da demanda escolar: concepções e práticas no estado de Minas Gerais. Gerais: Revista Interinstitucional de Psicologia, 5(1), 36-49.
Silva, S. M. C.; Silva, L.S.; Peretta, A.A.; Nasciutti, F.M.; Naves, F.F. (2014). As Diretrizes Curriculares Nacionais e a formação do estudante para atuar no campo educativo. In: Associação Brasileira de Psicologia Escolar e Educacional (Org), Anais do V Encontro Paranaense de Psicologia Escolar e Educacional (pp. 179-195). Maringá, PR.

Souza, C. S. (2010). A atuação do psicólogo escolar na rede particular de ensino da cidade de Uberlândia-MG. (Dissertação de mestrado). Universidade Federal de Uberlândia, Programa de Pós-Graduação em Psicologia, Uberlândia.

Souza, M. P. R. (2009). Psicologia Escolar e Educacional em busca de novas perspectivas. Psicologia Escolar e Educacional, 13(1), 179-182.

Souza, M. P. R.; Silva, S. M. C.; Yamamoto, K. (2014). Apresentação. In: Souza, M.P. R.; Silva, S.M. C.; Yamamoto, K. (Orgs.), Atuação do psicólogo na Educação Básica: concepções, práticas e desafios (pp. 9-11). Uberlândia: EDUFU.

Tanamachi, E. R.; Meira, M. E. M. (2003). A atuação do psicólogo como expressão do pensamento crítico em psicologia e educação. In: Meira, M. E. M.; Antunes; M. A. M. (Orgs.), Psicologia escolar: práticas críticas (pp. 11-62). São Paulo: Casa do Psicólogo.

Recebido: 31 de outubro de 2016

Aprovado: 12 de setembro de 2017

Artigo oriundo de dissertação de mestrado da primeira autora, sob orientação da segunda autora.

(cc) $\mathbf{E Y}$

License information: This is an open-access article distributed under the terms of the License (type CC-BY), which permits unrestricted use,distribution and reproduction in any medium, provided the original article is properly cited. 